HYBRIDA. Revue scientifique sur les hybridations culturelles et les identités migrantes

\title{
AVANT-PROPOS
}

\section{Sida, une épidémie presque oubliée}

uarante ans de sida : 38 millions de morts, 76 millions de personnes infectées. Une pandémie sans précédent à la fin $\mathrm{du} \mathrm{xx}^{\mathrm{e}}$ siècle, un succès thérapeutique inouï durant les vingt dernières années. Si le VIH a été l'évènement le plus important dans la compréhension des épidémies modernes, le monde se trouve face à une nouvelle épidémie, celle du Covid-19, qui n'a pas encore pris en compte les leçons acquises dans la douleur et l'activisme communautaire.

Sur le plan médical, le sida a été combattu grâce à une alliance inédite entre les médecins et les malades. Ce sont ces derniers qui sont parvenus à accélérer la recherche, en encourageant les protocoles compassionnels, et l'accès rapide pour les traitements expérimentaux qui ont sauvé des centaines de milliers de vies. La qualité des soins s'est améliorée, les hôpitaux ont adopté des règles universelles qui ont renforcé l'accueil et la prise en charge des personnes atteintes. Les essais cliniques ont évolué, permettant l'inclusion des minorités sexuelles et ethniques. La transmission de la mère à l'enfant a régressé. Les femmes, premières victimes du sida dans le monde, ont trouvé leur voix. L'accès aux traitements dans les pays pauvres a encouragé des génériques moins onéreux. La prévention a bénéficié d'immenses progrès comme la PrEP. Désormais, les personnes séropositives sous traitement pourront bénéficier d'un traitement tous les deux mois par voix injectable, une révolution qui paraissait

\section{Pour citer ce texte}

Lestrade, D. (2021). Avant-propos : Sida, une épidémie presque oubliée. Hybrida, (3), 9-14.

https://doi.org/10.7203/HYBRIDA.3.22915 
inimaginable il y a encore deux décennies. Avec tous ces outils, on espère la fin de la pandémie du sida pour 2030.

Et pourtant. Malgré ce succès, la mémoire du VIH s'évapore et les acquis obtenus semblent bien loin pour combattre le Covid. La parole des malades, si importante dans le sida, est invisible face à Omicron et les variants à venir. Les médecins et les experts ont repris le pouvoir et le quotidien des malades du Covid est caché par les médias ou les services hospitaliers. Des centaines de milliers de personnes sont mortes du Covid dans le silence, parfois loin de leurs familles et de leurs proches. Il n'y a pas eu de deuil lors de ces enterrements sommaires, il n'y a toujours pas de lieu du souvenir. C'est comme si le Covid moderne reprenait le cours du sida, dans les années 80, quand les malades étaient isolés, sans soutien extérieur, dans la terreur de la solitude.

Pire, la leçon fondamentale du sida, celle des brevets et des génériques des antirétroviraux, se heurte au monopole de l'industrie pharmaceutique qui contrôle les études cliniques, qui engrange des revenus pharamineux. Les pays en voie de développement, notamment en Afrique, disposent de peu de vaccins et d'équipement. Tout le monde s'accorde pour dire que la lutte contre le Covid exige une couverture vaccinale mondiale. Mais l'égoïsme occidental persiste et Omicron est désormais le résultat de cette incurie. Le Nord est privilégié, le Sud reste abandonné. Finalement, on dirait que les leçons apprises pendant les quatre décennies du sida ne nous permettent pas de répondre efficacement à la crise du Covid.

Cet échec présente de nombreux dangers sanitaires, mais aussi socio-culturels. Le mouvement anti-vaccin et contre le pass sanitaire reflète la mauvaise éducation face aux virus et les maladies transmissibles. Le succès de 120 battements par minute en 2017 et de la série It's a sin en 2021 montre que l'histoire du sida s'est évaporée, volontairement, à travers le désintérêt des pouvoirs publics. Les jeunes ne connaissent pas cette histoire car on ne les a pas préparés à se protéger des virus qui ne manqueront pas de se développer dans le futur, puisqu'ils sont tous la conséquence de la mondialisation, des voyages et des échanges commerciaux. Cette mémoire a été non entretenue par les gouvernements parce qu'elle symbolise la place des malades dans nos sociétés. Les centres communautaires de mémoire LGBT/sida sont encore trop rares, et cette culture n'est pas valorisée, précisément parce quelle vient de la base militante. Les activistes du sida ne sont pas reconnus. Le port du masque, c'est exactement la même chose que le port de la capote dans les années 80 et 90 . Une protection pour soi et pour les autres.

Les dangers du Covid sont les mêmes que les dangers du sida. L'apparition du Covid est aussi mystérieuse que celle du VIH en 1981. L'ignorance encourage l'épidémie. Le savoir est un pouvoir. En deux ans à peine, les relations sociales ont 
été bouleversées, les économies fragilisées, l'incertitude règne. La lutte contre le sida a été nourrie par l'espoir d'une médecine plus humaine, mais le Covid nous rappelle l'injustice de la société, où les décisions sont toujours prises au sommet de l'Etat. Les personnes malades ne sont jamais consultées, elles sont à la base d'une colère sourde qui se répand partout. Si le séropositif était un « réformateur social », le malade du Covid est sans voix. Les personnes les plus faibles sont les premières à décéder. Lépidémie actuelle accentue les disparités sociales.

Quarante ans de sida ont changé nos vies. C'est sûrement l'évènement le plus important de la mienne, avec des années de bénévolat et de militantisme. Je nose plus parler des ami.e.s disparu.e.s et de ce qui aurait pu être accompli si le sida ne les avait pas foudroyé·e.s. Je n'ose même plus parler de l'homme que j'ai le plus aimé dans ma vie, Jim Dolinsky, et notre histoire d'amour n'a duré que quatre années. Ce fut le sommet sentimental de ma vie, mais il est décédé en 1991. Sur les quatre années ensemble, il y a eu deux années de bonheur, suivies par deux années de maladie et de déchéance.

Que ce serait-il passé s'il avait survécu?

Serais-je toujours avec lui ?

Le monde serait-il meilleur?

Pourquoi ai-je survécu au VIH et pas lui ? 